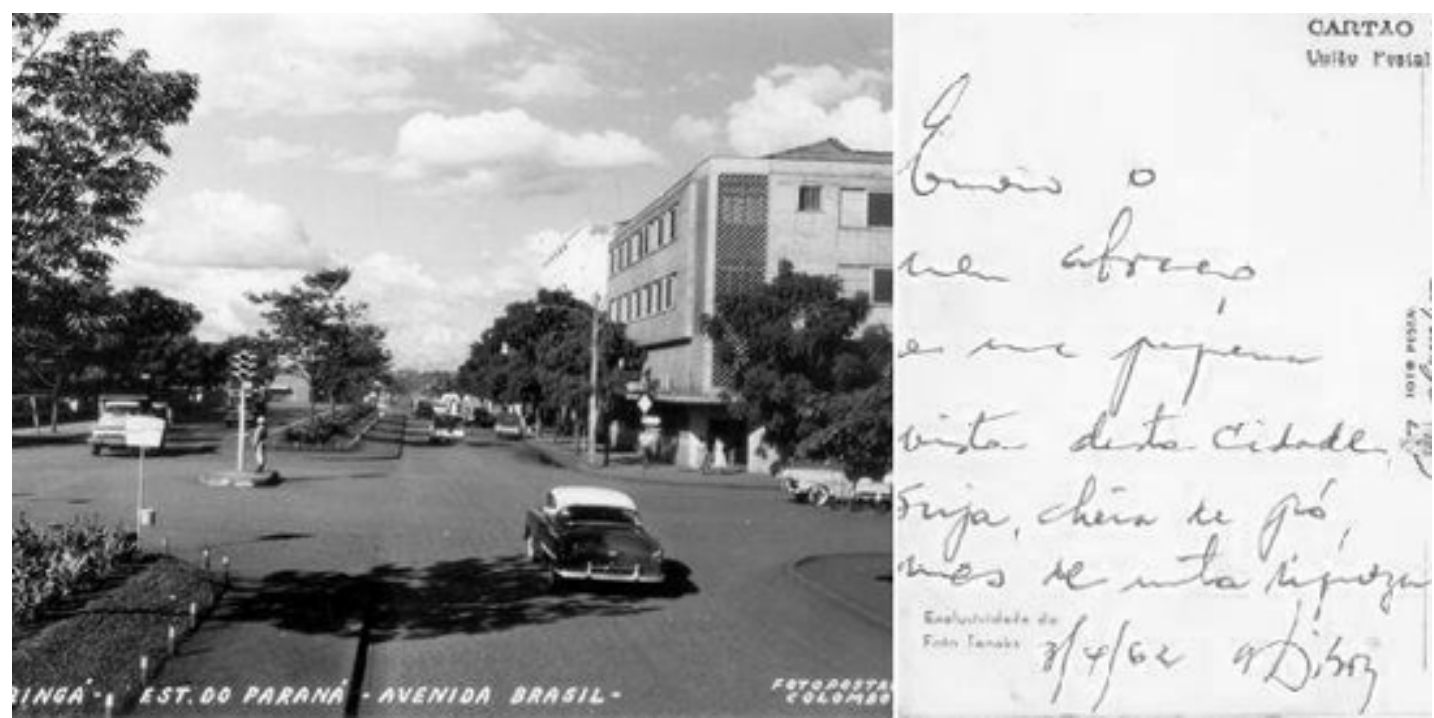

\title{
Cidade narrada, tempo vivido: estudos de etnografias da duração
}

(City told, Time lived: Studies in Ethnography of the Duration)

Ana Luiza Carvalho da Rocha* Cornelia Eckert**

\section{Resumo}

Para o estudo antropológico da memória coletiva no interior das modernas sociedades complexas propomos o desenvolvimento de uma etnografia da duração. Trata-se do estudo das imagens expresso nas narrativas dos habitantes das grandes cidades sobre seus territórios de vida em que constroem sentido de identidade em seus deslocamentos e pertenças. Filiamos-nos a uma antropologia das sociedades complexas, inspirada nos jogos da memória que orientam a fundação de comunidades urbanas em seus arranjos sociais. Problematizamos o ato da memória como ação no mundo temporal.

Palavras-chave: cidade, memória, narrativa, etnografia da duração

\section{Abstract}

For an anthropological study of collective memory within complex modern societies, we propose the development of an ethnography of the duration. It is the study of images expressed in the narratives of big cities inhabitants concerning their life territories. In these territories identity meanings are built while the inhabitants are moving and developing social bonds. Following the anthropology of complex societies inspired by memory games - such games orient the foundation of urban communities in their social arrays we analyze the memory act as action in the temporal world.

Keywords: city, memory, narrative, ethnography of the duration

\footnotetext{
* Instituição: Banco de Imagens e Efeitos Visuais, Laboratório de Antropologia Social, Programa de Pós-Graduação em Antropologia Social, Instituto de Filosofia e Ciências Humanas, Instituto Latino Americano de Estudos Avançados, Universidade Federal do Rio Grande do Sul. Endereço para correspondência: Rua Santa Terezinha 395 apto 11 90040180 - Porto Alegre RS. E-mail: miriabilis@ gmail.com

** Instituição: Banco de Imagens e Efeitos Visuais, Laboratório de Antropologia Social, Programa de Pós-Graduação em Antropologia Social, Instituto de Filosofia e Ciências Humanas, Instituto Latino Americano de Estudos Avançados, Universidade Federal do Rio Grande do Sul. Endereço para correspondência: Rua São Manuel 1660 apto 902 Porto Alegre 90620110 RS. E-mail: corneliaeckert@terra.com.br chicaeckert@gmail.com
} 
Imagens da cidade vivida povoam nossas memórias. Caminhamos pela cidade e percebemos em nós sentimentos diversos sobre pessoas de nossa rede de pertença (e outras que estranhamos), sobre ruas que nos são familiares (evitamos outras), sobre espaços freqüentados (ignoramos outros), sobre transeuntes que nos atiram a atenção (evitamos a proximidade com alguns), enfim, estes tantos arranjos sociais nos configuram um sentido de ser e estar na cidade. São nestas formas de perceber a cidade que tecemos nossas rotinas, traçamos nossos percursos, planejamos nossos afazeres, enfrentamos nossos temores e constrangimentos. A cada dia, cidadãos perfazem seus deslocamentos para o trabalho, para o lazer, para seus compromissos ou desocupações. A descrição da cidade que somos nós e que está em nós, é uma narrativa que se transforma no jogo da memória de seus habitantes tanto quanto do etnógrafo que reinterpreta as interpretações dos habitantes que pesquisa em suas trajetórias.

Nesse artigo, baseamo-nos nos dados do nosso projeto de pesquisa antropológica sobre a memória coletiva dos habitantes da cidade de Porto Alegre, iniciada em 1997 no âmbito de um núcleo de estudos que denominamos Banco de Imagens e Efeitos Visuais www.biev.ufrgs.br (PPGAS, IFCH e ILEA, UFRGS).

A pesquisa antropológica em contextos urbanos emerge e se consolida no século XX. O mote da pesquisa antropológica, sobretudo através do seu método etnográfico, consiste em observar e entrevistar estes citadinos em seus cotidianos. Compreendemos assim que, para conhecer a cidade como fenômeno social, nós pesquisamos a memória de indivíduos e grupos a partir das narrativas e das trajetórias destes habitantes nas mais diversas situações de convivência informal ou formal, pública e privada. Em termos de procedimentos metodológicos investimos nos estudos de narrativas das trajetórias e itinerários dos habitantes na cidade pela imersão do etnógrafo na "memória dos passos perdidos" (DE CERTEAU, 1992) dos moradores como topos significativo da re-recriação de tradições urbanas. As paisagens urbanas despontando como espaços fantásticos onde os moradores de um grande centro urbano, habitando suas lembranças passadas, fazem das imagens imateriais de seu acervo patrimonial um conhecimento em ato da cidade (DURAND, 1984).

No nosso campo de conhecimento, os habitantes na cidade são narradores em potencial de suas experiências vividas no contexto urbano. Mesmo em suas discursividades em que predominam lógicas ideologizadas pela mídia, dimensionamos na instância de um 
tempo narrativo, o trabalho da memória em que os habitantes ordenam sentidos de práticas coletivas. Certo, alguns fazem suas as palavras de uma estrutura de poder discursivo, moral e legalista. Neste mimetismo das representações dominantes, pouco podemos negociar por um jogo de memórias que não se limite a reprodução de racionalidades sobre a cidade legalizada. Mas, em face do habitante que aceita compartilhar suas interpretações, o tempo vivido na cidade se torna mote de narrativas que operam as formas do pensamento ordenar as descontinuidades dos ritmos cotidianos. Assim, ao narrarmos nós, as formas do viver urbano em Porto Alegre, reconhecemos os citadinos como uma comunidade interpretativa no âmbito de um campo semântico, no qual também o pesquisador em suas interpretações, é configurador de um pensamento sobre as formas dos tempos vividos nas cidades.

O porto-alegrense nesta narrativa interpretativa pode ultrapassar os símbolos que o culturalizam em emblemas identitários. Como sugere Marcel Proust tantas vezes retomado por Walter Benjamin, na ação do habitante narrar-se na interlocução as memórias da cidade, a "identidade-mesmidade" é destruída, o que significa "a renúncia à discursividade linear" e que acarreta "uma alteridade sempre renovada do objeto" (apud GAGNEBIN, 1999: 147-8). O citadino motivado a evocar suas memórias e imagens no fluxo do relato biográfico, se reinventa como sujeito que narra situações-eventos (SAHLINS, 1985) de suas experiências vividas no contexto citadino como trama de construção de sentidos de um "si-mesmo", narrativas estas que não estão desprovidas de toda dimensão normativa, valorativa, prescritiva e ética (RICOEUR, 1991). A narrativa, aliás, já pertence ao campo ético em virtude da pretensão, inseparável da narração, à correção ética (RICOEUR, 1997: 429).

Nas cidades moderno-contemporâneas são inúmeras e distintas as tradições narrativas segundo as quais a vida urbana é interpretada. Mas o antropólogo, em seu ofício de pesquisar na cidade, parte de uma perspectiva metodológica interpretativa específica para configurar um grupo de interesse de estudo. Esta perspectiva da prática etnográfica postula uma aproximação e convivência, onde o pesquisador compartilha, na experiência etnográfica, o fluxo cotidiano de pessoas pesquisadas. No consentimento da experiência compartilhada, o tempo de convivência torna-se mais denso tanto quanto densa se torna a demanda de observar situações vividas e de escutar suas falas. 
O pesquisador, mediante seu narrador, agencia uma interlocução para arranjar um cenário de evocações em que o habitante pode "transcriar" imagens e formas de ler a si na cidade refigurada no tempo da narrativa. Neste jogo de reciprocidade cognitiva, o problema da refiguração do tempo pela narrativa se vê transportado para o nível de uma ampla confrontação entre uma aporética da temporalidade e uma poética da narratividade (RICOEUR, 1991: 8).

Esta declaração epistemológica nos faz seguidoras de categorias arquitetadas por Paul Ricoeur em sua obra $O$ si-mesmo como um outro em que o narrador é vulnerável à ação do tempo que o constrói na "ipseidade" (reconhecer-se a si mesmo, no tempo narrativo) ultrapassando a identidade-mesmidade sobre os traços da experiência temporal que separam identidade-idem e a identidade-ipse na formulação da identidade pessoal. A noção de identidade narrativa só ocorre no processo de ipseidade, tal qual arquiteta Ricoeur, uma distensão no tempo da identidade de um si-mesmo relacional, que supera as classificações dicotômicas, as identidades fixas, abrindo-se no circulo hermenêutico, a palavra do mundo em sua circularidade e reciprocidade.

Nesta acepção, não são as representações sobre a cidade em suas lógicas e feitos externos que o habitante racionaliza, mas a interpretação que faz de sua própria experiência de sujeito da memória que o inscreve num mundo amalgamado de sistemas práticos e sistemas simbólicos. O narrador que pulsa a cidade em sua voz e em sua escrita (no caso de autobiografias, crônicas, contos, entrevistas escritas etc.) momentaneamente ordena e ultrapassa as "identidades emblemáticas" (referência a Émile Durkheim) e "identidades contrastivas" (referência a Pierre Bourdieu) que o aprisionam na analogia e na reprodução da mesmidade, para se estender agora em uma "identidade narrativa" (RICOEUR, 1997). Nesta obra de restauro da narrativa, se estabelece o gesto necessário para impor um tempo que flui como inconstante no trajeto humano e que contempla "as representações subjetivas explicadas pelas acomodações anteriores do sujeito ao meio objetivo" (Piaget citado por DURAND, 1989: 30).

A noção de identidade narrativa de Paul Ricoeur é que nos permite articular a dimensão temporal da existência humana com a constituição do conhecimento de si na experiência narrativa, posto que, para o autor, a identidade narrativa consiste em uma

\footnotetext{
${ }^{1}$ Referência ao poeta concretista Haroldo de Campos.
} 
estrutura da experiência capaz de integrar a narrativa do mundo e a narrativa de si, a narrativa histórica e a narrativa de ficção (RICOEUR, 1998: 138), o que nos orienta ao estudo da identidade narrativa como permitindo ao citadino a interpretação de si, conhecendo-se como sujeito de sua biografia no deslocamento narrativo.

Criticando a tradição filosófica que privilegia o aporte egológico da experiência mnemônica, Ricoeur elabora questões nesta ordem: primeiro "o que lembramos?, seguido da pergunta "quem lembra"?, e, por fim, lança o questionamento "como lembramos"? Paul Ricoeur aqui é claramente crítico à perspectiva da história de vida como método autônomo que confunde a memória de quem narra com uma fenomenologia da memória. Evita-se assim perceber a história de uma cidade presa às modalidades simbólicas de controle do tempo expressas pelos grupos/indivíduos e agenciadas no contexto de seus ambientes psico-históricos. Justamente para romper com a memória da lembrança como uma questão egológica, Ricoeur propõe uma distinção no âmbito do ato da memória das questões "o que" lembramos, "como lembramos" e "quem lembra", correlacionando o ato (noese) do correlato visado (noeme) (RICOEUR, 2000: 27), ou seja, distinguindo entre a noese que é a rememoração e o noema que é a lembrança.

Não há assim confusão entre a história da cidade e a memória restaurada na narrativa dos habitantes que tomam a cidade como objeto temporal. Narram sobre o cotidiano, sobre formas de sociabilidade, trajetórias e estilos de interagir e de pertencer, de distinguir e de conviver na cidade que os abriga. Mas essa cidade também os narra, uma representação mais ampla que ultrapassa redes e comunidades locais. Para tanto os habitantes narram esta experiência de acomodar em múltiplas camadas do tempo vivido as trajetórias pensadas. Como sujeitos da ação, narram o quem da ação (RICOEUR, 2000: 424). Ao narrar se constrói como sujeito da ação vivida com significação no presente a partir das imagens que reiteram a questão "como lembramos": "A identidade do quem é apenas, portanto, uma identidade narrativa" (ibid.). Mas uma identidade que não se perde na egológica da experiência mnemônica, compreendida no sentido de um mesmo (id.), mas uma narrativa que restitui a inteligibilidade dos sentidos "compreendida no sentido de um si mesmo (ipse)" (ibid...425). 
Nesse ínterim do estudo da memória vivida no âmbito da identidade narrativa dos habitantes na cidade, cabe recorrer a Georg Simmel em sua teoria sobre a ação recíproca entre indivíduo e sociedade, entre micro situações e macro processos estruturais no mundo moderno, entre forma e discurso (SIMMEL, 2006). Em Simmel a vida social urbana é tema de estudo em suas formas, ou seja, a vida social é resultado mais de uma causalidade formal do que de uma causalidade material. Nesse sentido, podemos postular, seguindo o autor, de que toda a continuidade da forma de um corpo social está associada ao fundamento psicológico da representação de si-no-mundo.

Esta qualidade de tratar da vida dos habitantes na cidade os situa em suas subjetividades, como protagonistas de trajetórias pessoais e de constrangimentos que elucidam sobre a condição de indivíduo no mundo moderno contemporâneo. Mas igualmente os situam como sujeitos da cultura objetiva orientada pelo ritmo da vida urbana em suas estruturas e dinâmicas institucionais.

Há, aqui, de nossa arte, filiação ao princípio metodológico de Georg Simmel (1934), do ato recíproco entre cultura subjetiva e cultura objetiva. No jogar o social, como diria Georg Simmel para definir a sociedade, importa situar o esforço da produção de sentido que relacione o indivíduo à coletividade, que situe o urbano no social, que mapeie as ações de sujeitos na cidade aos valores éticos, em que embasam seus projetos de vida e formas de interagir no mundo social.

É nesta condição dialética que buscamos desenvolver exercícios etnográficos sobre as mais diversas situações sociais vividas no cenário urbano. É nos relatos de vida destes citadinos apreendidos em suas narrativas que procedemos a interpretação das formas de viver sociabilidades e interações nos ritmos da vida cotidiana.

Essa prática é oriunda do campo de conhecimento da antropologia, colocando em interface as especificidades temáticas da antropologia dita urbana, antropologia dita visual e a antropologia dita do imaginário. Neste entrelaçamento de linhas de pesquisa, nosso projeto epistemológico tem por orientação a tese da dialética da duração definida pelo saber bachelardiano que evoca, para o estudo da memória coletiva, o tratamento dos fenômenos da duração construídos como ritmos. Diz Gastón Bachelard:

Para durarmos, é preciso então que confiemos em ritmos, ou seja, em sistemas de instantes. Os acontecimentos excepcionais devem encontrar ressonâncias em nós para marcar-nos profundamente. Desta frase banal - 'a vida é harmonia' -, 
ousaríamos então finalmente fazer uma verdade. Sem harmonia, sem dialética regulada, sem ritmo, nenhuma vida, nenhum pensamento pode ser estável e seguro: o repouso é uma vibração feliz. (BACHELARD, 1988: 9).

Podemos agora argumentar que adotamos como chave interpretativa o ponto de vista da cidade como objeto temporal em suas modalidades narrativas. Ou seja, consideramos que a cidade e seus arranjos da vida social, no contexto das atuais modernas sociedades complexas, devem ser pensados desde a perspectiva das durações de instantes descontínuos que orientam a experiência humana de seus habitantes, os quais, além de serem atores e autores, também assumem o lugar de personagens da vida urbana. Mas trata-se de personagens com qualidade narrativa, ou seja, personagens-narradores da vida urbana.

Cada experiência etnográfica consiste para o antropólogo em seu ofício em observar, escutar e escrever sobre um vínculo que se estabelece entre o pesquisador e seu universo de pesquisa de forma que haja reconhecimento deste trabalho, consentimento informado e interlocução no processo, permitindo não apenas a leitura da cidade por parte do pesquisador, familiarizado com o contexto urbano, mas de um contrato de interlocução com os habitantes como um jogo de reciprocidades (solidária ou agonística) que se estabelece no tempo do convívio da pesquisa.

As pesquisas de campo implicam engajamento dos pesquisadores nas rotinas urbanas de pessoas, grupos e acontecimentos ora banais, ora extraordinários, ora públicos ou mais privados ao mundo doméstico. Situações diversas que implicam inserção dos pesquisadores nos processos de interação que configuram as formas da vida social, como nos ensina Georg Simmel no conjunto de sua obra. Trazemos por exemplos os exercícios etnográficos no projeto de pesquisa BIEV (1997-2009) no âmbito do Programa de Pós-Graduação em Antropologia Social (IFCH e ILEA, UFRGS), coordenado pelas autoras. São os dados desse projeto compartilhado, vários entre eles na forma de documentários fílmicos, que selecionamos para exemplificar neste artigo

O trabalho de mestrado de Lucas Graeff, por nós orientado, apresenta um capítulo em imagens a partir da edição de narrativas fotográficas e do som das entrevistas. Lucas desenvolveu um estudo antropológico sobre memória social e cotidiano de velhos no Asilo Padre Cacique, em Porto Alegre. Nessa pesquisa etnográfica realizada entre agosto de 2004 
e dezembro de 2005, ele conviveu com idosos do asilo através de visitas sistemáticas, observando suas rotinas e escutando suas histórias sobre suas condições de vida, suas trajetórias pessoais, familiares e institucionais, conhecendo a forma singular de interpretarem seus tempos vividos, agora narrados como velhos que pensam o tempo e reinventam sua velhice no cotidiano asilar. No pátio, na ala feminina, na ala masculina, no refeitório, na capela, no subsolo, na enfermaria, na recepção, em todas as instâncias espaciais que conformam a condição de viver asilado, o pesquisador enfatizou o trabalho da memória destes personagens que aceitaram narrar para Lucas suas experiências de vida nessa condição de envelhecimento.

É nessa atualização das experiências vividas na forma narrativa, nesses momentos biográficos, que Lucas pode ouvir e reordenar a história de vários personagens. Trazemos dois parágrafos da própria dissertação para orientar o que queremos destacar em seguida:

\begin{abstract}
A memória e o cotidiano imprimem uma temporalidade específica à experiência de envelhecer no asilo. Em cada lugar e momento, ritmos diferentes se impõem: eles estão intimamente relacionados às ocupações dos espaços sociais e às relações afetivas estabelecidas no presente, que servirão de apoio coletivo para a evocação das lembranças. As festas, os jogos, o lazer e a sociabilidade[...] são momentos de efervescência social, que extravasam os hábitos e rotinas diárias e enquadram socialmente a memória. Por essa razão, o acesso as diversas camadas de sentido da condição de envelhecer no asilo depende da participação nos ritmos sociais da instituição.

A temporalidade do Asilo Padre Cacique foi uma chave interpretativa para compreender as minúcias do contexto asilar: as "táticas cotidianas", que tangenciam as regras institucionais e tornam o asilo "habitável" (De Certeau, 1996); as várias práticas e saberes, constituídos durante a vida de cada velho e legitimados frente ao pesquisador através da narrativa, que explicam a apropriação de outros espaços sociais além da cama, do armário e da cadeira no refeitório; e a reinvenção de trajetórias sociais através da memória, espaço do fantástico (Eckert e Rocha, 2000c), possível justamente pela ruptura com as redes sociais anteriores à entrada no asilo. (GRAEFF, 2005: 12)
\end{abstract}

Lucas procede a uma familiarização com moradores do asilo e conhecemos, em seu trabalho visual e sonoro, Pedro, Marieta, Azevedo, Luduvica, Rui e Lidia, que se tornam interlocutores da pesquisa interpretando suas vidas no asilo. Cada narrador se constrói como um personagem na cidade. Não há um discurso sobre o determinismo de ser velho no asilo, mas relatos de tempos vividos e lembrados de si mesmo no âmbito de uma vida coletiva e compartilhada de significações. Em cada narrativa biográfica, as redes anteriores 
à entrada no asilo desvelam trajetórias e experiências na vida urbana de Porto Alegre em suas continuidades e descontinuidades.

Pedro testemunha para Lucas trajetórias de trabalho na cidade de Porto Alegre como garçom. Fotos com patrões, colegas, mas também com autoridades que freqüentaram o restaurante onde trabalhava, corroboram o convívio com uma rede de pessoas públicas. Um vereador que era amigo situa partidos políticos de conjunturas históricas anteriores. Já Marieta ordena sua narrativa a partir de experiências geracionais da vida cultural. A força do rádio no século passado em seus programas de calouros é lembrada na voz fraca de Marieta entre versos de marchas carnavalescas. Uma Porto Alegre dos anos 1950 a 1960 aparecem nas canções, no relato de carnavais de rua e de clubes em suas festas e fantasias. Adereços de uma fantasia fazem, aliás, parte de sua performance para restaurar a Lucas, o ethos de sua atuação profissional como cantora e dançarina da Rádio Difusora em Porto Alegre.

Luduvica e Azevedo abrem armários, caixas e álbuns para trazer a Lucas fotografias e cartas que figuram suas trajetórias na cidade. Imagens mentais "estetizam" cenas sociais vividas como sujeitos biográficos. Os atores elaboram cenas sociais de pertença a redes familiares em suas dramáticas. Nessas trajetórias, atribuições de acontecimentos históricos na cidade, no país, servem para justificar vulnerabilidades e crises familiares. Rui mistura dramáticas pessoais e intrigas de suas leituras literárias densas, e a justificativa de um armário tomado de livros, medalhas e outros objetos pessoais de sua antiga morada. Nesta densidade interpreta o sentido de si mediante uma estrutura de significações e determinações sociais que nos remetem a conjunturas políticas e históricas em Porto Alegre.

Lucas constrói o seu relato etnográfico de uma duração a partir de imagens fotográficas de cada personagem e de suas narrativas biográficas gravadas em vídeo. Na posição de pesquisador, as narrativas são "transcriadas" em imagens visuais e sonoras qualificadas pelo evento etnográfico. Ao final, os personagens são restituídos em suas inteligibilidades narrativas no suporte de um DVD, num texto povoado de uma escrita alegórica, compondo um dos capítulos de sua dissertação de mestrado. Pode-se, na condição de leitoras de sua obra, conhecer a condição de vidas em Porto Alegre, em suas 
trajetórias ritmadas por descontinuidades que mapeiam a cidade em sua pluralidade e complexidade.

O capítulo em DVD situa as narrativas de alguns moradores do Asilo Padre Cacique, em Porto Alegre, como relatos que se interpretam. Para cada um deles, ao se olhar para a seqüência das fotos, agenciadas uma por causa da outra, reconhecemos a acomodação rítmica de uma biografia. Assim, essas imagens contemplam a interpretação de Pedro, de Ludovica, Lídia, Azevedo, Marieta, em suas vozes, seus cantos, suas performances, seus gestos, mas também silêncios, esquecimentos e emoções que são reinterpretados pelo antropólogo em sua escuta ordenada agora em um caráter semântico. Podemos aqui aprofundar para vocês o quanto o pesquisador busca, neste procedimento de narrativa audiovisual, "transcriar", "as homologias simbólicas que constelam um mesmo tema arquetipal de imagens" (DURAND, 1989: 31) em torno do qual cada uma das vidas recontadas orbita e adquire sentido.

Para nós, evidentemente, o que este trabalho de pesquisa revela é a importância de se perscrutar uma etnografia da duração na descoberta da uma identidade narrativa para cada um dos personagens e o lugar que o Asilo Padre Cacique e a própria cidade nela ocupam. Uma especificidade de pesquisa antropológica no contexto urbano para o qual seguimos a teoria de Gastón Bachelard. Estreitamente aderentes às reflexões sobre o imaginário, o tempo e a memória de tais autores, para nós a etnografia da duração se origina, no plano dos jogos da memória, na descrição do movimento e da construção produtiva da vida, gerada a partir de esquemas de pensamento singulares diante dos ultrajes que o tempo lhe submete. As condições epistemológicas para compreender o fenômeno temporal consiste em tratar a memória encerrando os movimentos do pensamento, como fruto de uma construção produtiva e criadora de conhecimento; ela é a expressão, no plano da imaginação criadora, das estruturas dinâmicas da inteligência (ECKERT \& ROCHA, 2005).

De forma mais ampla, podemos sugerir que adotamos para a análise da cidade como objeto temporal as reflexões de Gilbert Durand (1984) e Pierre Sansot (1997) ao situar a produção do fenômeno urbano como parte do trajeto antropológico do homem, e de sua dimensão poética dos arranjos de suas formas, ou seja, o fruto das acomodações das pulsões subjetivas humanas às intimações do seu meio cósmico e social (DURAND, 1984: 30). O 
espaço urbano aparece, assim, como parte da expressão de uma "fantástica transcendental", onde se situa o fenômeno da memória, ao permitir aos seus habitantes "remontar o tempo" e perenizar suas ações no mundo (apud ECKERT \& ROCHA, 2005).

No interior de uma etnografia da duração somos desafiados(as) a compartilhar as imagens narradas pelo antropólogo desde o seu encontro etnográfico com o outro e, ao mesmo tempo, convidados a compartilhar nossas próprias imagens e experiências de viver a cidade, resultando, ao final, no entrelaçamento de memórias plurais das quais nasce a cidade como parte integrante de uma comunidade semântica em suas múltiplas interpretações. Não se trata, portanto, de um relato histórico onde o que é narrado nas entrevistas exemplifica ou explica a vida num asilo qualquer, em Porto Alegre, nem sequer retrata a história de um território da vida urbana portoalegrense na forma de um patrimônio externo à vida daqueles que nele habitam. Há, sem dúvida, evocação da vida objetiva sobre o ato de envelhecer numa grande metrópole contemporânea, mas a cidade é convocada, nos relatos dos idosos, como arranjo poético de suas vidas vividas. Ou seja, onde o tempo é arranjado na perspectiva da compreensão das histórias por eles relatadas segundo o fluxo de suas identidades narrativas, ou, como refere Paul Ricoeur, "ora narração histórica ora variação imaginativa, a identidade narrativa não cessa de se fazer e de se desfazer" (RICOEUR, 1998: 428).

Podemos avançar assim na definição de duração nos termos de Gastón Bachelard, para quem a matéria e a vida não se traduzem na simples oposição de sujeito e objeto, elas se reconciliam no movimento de troca incessante entre ambos e, na ausência de um, ainda está lá, automaticamente, a presença do outro. Atendendo-se à idéia de que o tempo é hesitação, assim como a continuidade substancial da matéria só intervém tardiamente, a compreensão da duração bachelardiana exige do estudioso da memória uma singular atenção à vacuidade e à hesitação tanto da matéria quanto da vida, exigindo-lhe uma recusa da idéia ingênua da plenitude do mundo das coisas, posto que a idéia da continuidade do tempo não é um dado em si mesmo, mas uma obra (ECKERT \& ROCHA, 2005 referindose ao estudo de Bachelard, 1988).

Portanto, as narrativas, biográficas ou não, construídas na etnografia da duração, intensificam o tempo vivido na cidade, dando espessura ao jogo de memórias. Nos termos 
de Walter Benjamin, diríamos que o passado é salvo, no presente, por intermédio do próprio ato da escrita do pesquisador que descobre os rastros de um futuro pressentido, sem que o conheçamos (apud GABNEBIN, 1999: 89). Consideramos pertinente trazer a referência de Gabnebin, em seu estudo da noção de história e narração em Walter Benjamin, principalmente quando se refere à obra de Peter Szondi sobre o narrador na "busca de um futuro anterior". Nesse processo, os relatos biográficos, e na dimensão de identidade narrativa, por sua qualidade peculiar de subverter discursos linearizantes de uma cidade-matéria, postula por uma sabedoria onde "não há nada de idealizante ou de estetizante, mas que é, arrisquemos a palavra, profundamente político" (GABNEBIN, 1999: 89).

Neste sentido, a etnografia da duração, grávida desta condição política, faz concordar entre si os símbolos que constituem esta experiência temporal. Neste fluxo, os sujeitos narradores, em suas situações biográficas, reencontram e reconhecem a identidade do "si mesmo" (a "ipseidade"), sensibilizados que estão ao conhecimento de si na condição de sujeitos da cidade para o qual se abrem em dimensões inconscientes mas também altamente transformadoras. As cidades evocadas nos jogos de memória de seus habitantes são por nós contempladas na perspectiva das ditas "hermenêuticas instauradoras" (DURAND, 1988), ou seja, espaços de vida onde o fenômeno da ipseidade, integrando as suas narrativas desde um deslocamento essencial, lhes permite reconhecerem-se no tempo no qual vibra a história presente.

Assim como os sujeitos da pesquisa, o próprio etnógrafo, em campo, no contato com seus relatos, se modifica uma vez que sua escuta o força a um deslocamento constante na interpretação das identidades do "si mesmo" dos narradores participantes dos eventos etnográficos, posto que estamos diante de um perpétuo deslocamento de "si", e que ele postula para o etnógrafo em campo uma alteridade que não é fixa, mas é processo contínuo de reinterpretação, reconstruindo sempre o "si mesmo" a partir da atualidade do evento etnográfico.

Num tal contexto de pesquisa, o da etnografia da duração, os efeitos de realidade que presidem a narrativa etnográfica ancoram-se, ao mesmo tempo, por um lado, na "biografia cognitiva" do antropólogo, ou seja, da ordem da lógica, ou do percurso objetivante de seu pensamento diante do fenômeno por ele investigado e, por outro, de ordem dramática, isto 
é, dos processos subjetivantes a partir dos quais ele designa um sentido a uma série de acontecimentos e situações vividas por ele com seus sujeitos de pesquisa, durante a realização de seu trabalho de campo. Ao final, o ato reflexivo da escrita etnográfica é precedido pela experiência de interação consentida e da escuta atenta do interlocutor que aceita o jogo de trocas que se consolidam nos "encontros etnográficos".

Ao longo de seu trabalho de campo, quanto mais esquecido de si mesmo, mais profundamente o antropólogo escuta a voz de quem conta, atingindo assim a visão compartilhada daquilo que lhe é contado. A etnografia da duração realizada pelo antropólogo é, assim, devedora das histórias vividas que lhe foram transmitidas e das quais nós, antropólogos, nos apropriamos para produzir teorias e conceitos desde nossa matriz disciplinar. Narramos histórias vividas quando produzimos descrições etnográficas e, com isso, evocamos essas reminiscências seja por meio da escrita, de fotografias, de vídeos ou de filmes.

No sentido de uma etnografia da duração, cada acontecimento vem a ser a condição de interpretação da prática antropológica, cabendo ao antropólogo-pesquisador enfocar, em sua escrita, em sua crônica videográfica ou sonora, ou em seu ensaio fotográfico, a lógica do compartilhamento de suas reminiscências com aquele do qual esta matéria lembrada e evocada resulta. Em outras palavras, implica ao antropólogo se disponibilizar ao papel, em termos epistemológicos, de "guardião" da memória dos grupos com os quais trabalha ou de agente de sua reatualização e retransmissão. Precisamente, tais demandas, de reatualização e de retransmissão no presente de uma matéria para passado, têm apontado, cada vez mais, para o lugar delicado de "mediação cultural" que configura a prática da etnografia nas modernas sociedades complexas.

O encontro etnográfico, portanto, traz este desafio, nos termos benjaminianos: o "dom da escuta", pois todo o relato sobre os territórios vividos numa grande metrópole acompanham o ato de caminhar na cidade de seus habitantes, lembrando ao etnógrafo a relevância do ato de flannerie como ato que integra a compreensão da vida urbana. Seja pelo ritmo dos deslocamentos que uma grande metrópole encerra como parte de um tempo vertiginoso, seja nos "pontos de amarração" (BOSI, 1987) das lembranças e reminiscências que seus lugares nos ensejam a recordar. 
Esta sensibilidade para a captura da imagem da forma para o ato de compreensão de viver o contexto citadino, no remete aos comentários que nos faz Georg Simmel (1981: 235) em sua "sociologia dos sentidos", sobre o princípio contraditorial que reúne o olhar e a escuta. Para o autor, o olhar, diferentemente do ouvir (egoísta em sua natureza), não pode se apropriar do sentido daquilo que por ele é visto se não for entregando-se a imagem - não se pode possuir o visível, pode-se, sim, compartilhá-lo (neste ponto o olhar é disponível ao encontro, a partilha de sentidos). Entretanto, mais do que pensá-los (olho e ouvido) como antagônicos, Georg Simmel nos permite pensar que os gestos que deles derivam - de ver e de ouvir -, são partes de um todo, permitindo-nos, neste ponto, aperfeiçoar a prática da etnografia da duração na confluência de ambos, seguindo-se, assim, o princípio interno e precário de (con)figuração da vida no social, na polaridade entre vida objetiva e vida subjetiva.

Com Simmel, podemos tratar a etnografia da duração sob o ponto de vista das figurações da forma do ser do social tecida nas narrativas biográficas e nos itinerários urbanos de nossos sujeitos de pesquisa. Figurações de formas contempladas no ato de narrar por meio do qual podemos pensar a imagem substancial do ser do social numa grande metrópole como o sedimento de uma multiplicidade de tempos passados, consolidados, no presente, numa duração. Isto é, a vida urbana transcorre diante dos olhos e ouvidos atentos do etnógrafo como a figuração de uma sucessão de atos de uma vida inteira.

Em seus comentários sobre os traços figurativos, e o órgão visual, para a construção da unidade estável da alma de unidade coletiva, este autor, entretanto, nos brinda com uma importante derivação do assunto para o que estamos refletindo aqui, sobre a dialética da duração e seus estreitos laços com os estudos do imaginário. Ao tratar, especificamente, das relações entre a visibilidade/visualidade da forma do ser social para o caso das categorias de entendimento da cultura, Georg Simmel (1981: 230) se confronta com o tema do cego e da cegueira. Nesse ínterim, a forma do ser não se dá a ver em sua dimensão figurativa. Uma complexidade que remete, segundo este autor, ao caráter enigmático de devaneio que toda forma contempla. O que lhe permite concluir, em sua sociologia dos sentidos, que o conhecimento do ser do social exige o desapego do cientista social da camada superficial do tecido por meio do qual todo o corpo social se apresenta. Numa metáfora, trata-se de 
ultrapassar as condições concretas e materiais por intermédio das quais o ser social se dá a ver, para aderir progressivamente às suas outras camadas profundas, até atingir as forças criativas dos fios delicados e invisíveis de sua urdidura. Para o que estamos tratando neste artigo, o que queremos ressaltar é que Georg Simmel reconhece a importância estrutural da "unidade coletiva" numa forma - através da participação das imagens, complementaríamos. Vemos aqui as preocupações singulares do autor a respeito do valor sociológico do lugar da figura e da recíproca do olhar no "jogar o social” (ou das figurações do social, diríamos nós).

Assim que, para nós, a grande metrópole contemporânea, em sua fuga do tempo, se dá a ler não como uma escrita realista e cronológica, mas através de narrativas biográficas, trajetórias sociais, práticas e saberes, itinerários urbanos, projetos de vida que mais lembram partituras em sucessões rítmicas. Um fenômeno que desencadeia no etnógrafo atento a idéia de que toda a vida urbana carrega um decurso temporal no bojo das descontinuidades que ela apresenta, em termos espaciais. As cidades modernocontemporâneas podem ser enfocadas como fenômeno singular, isto é, espaço onde o tempo revela-se como hesitação. É, neste ponto, que podemos reivindicar para o estudo da etnografia da duração o que Gastón Bachelard sugere como estudo de "ritmanálise". Para se interpretar a vida vivida pelos habitantes de um grande centro urbano-industrial torna-se relevante se compreender as lacunas do tempo como condição de seu ato de consolidação em duração (BACHELARD, 1988).

Outro exemplo de experiência etnográfica reforça alguns dos pontos mencionados acima. Retornamos a uma inserção de campo vivida em 2002, quando visitamos um casal de idosos, ambos pertencentes às camadas médias urbanas, nascidos em Porto Alegre e atualmente moradores do bairro Santana. O contato para a entrevista decorreu em razão de serem vizinhos de uma das autoras, já tendo com ela laços estreitos de vizinhança. A aproximação para entrevistá-los surge de um projeto sobre medo e vulnerabilidade vivido por idosos em Porto Alegre. Sendo consultados a respeito do tema, eles aceitam sem delongas colaborar. As entrevistas e conversas ocorrem sem formalidades e sem pressa, graças a sua disponibilidade de aposentados. 
O drama específico que motiva a entrevista ocorreu com o casal no final dos anos 90 quando ainda moravam em uma casa no bairro Partenon, uma habitação comprada para ser a feliz morada da família, um casal e dois filhos. A vizinhança era bem quista com a vantagem da proximidade da casa da avó materna. Num final de semana, ladrões encostaram um caminhão de mudança. Entraram pelo telhado e levaram um importante patrimônio pessoal. Na avaliação de Dona Emma, a decepção foi de que os vizinhos sabiam que eles não estavam de mudança e nem perguntaram do que se tratava aquele caminhão em pleno domingo. "Para que servem vizinhos então? A gente se dava bem com todo mundo. Nunca falamos em nos mudar. Sabiam que sempre íamos para praia, e nunca falamos em mudança", sentencia amargurada. Mas para Dona Emma, em sua narrativa: “o pior foi terem levado todas as nossas lembranças, presentes de casamento, herança dos nossos pais, louças e bibelôs, toda minha coleção, além do estrago, da quebração e da sujeira que deixaram." O sentimento de constrangimento e de insegurança lhes causa trauma pelas "lembranças roubadas".

Em razão do ocorrido, tomam a decisão de desfazer-se da casa e de comprarem um pequeno apartamento para onde se mudam com o que sobrou. $\mathrm{O}$ deslocamento de bairros é do Partenon para o bairro Santana, agora próximo ao "quartel” (depósito do Quartel General da III Região Militar, situado na Rua Santana, próximo ao edifício onde moram), e onde dizem se sentir mais seguros. O prédio onde moravam era um edifício típico das construções dos anos 70, bastante funcional, com um espaço, improvisado no terreno, para acomodar o carro do casal. Um prédio com cerca alta, alarme e porteiro eletrônico, lhes dá algumas garantias de proteção. É nesse apartamento, localizado no segundo andar, que realizamos as entrevistas. Na sala, trabalhos artesanais pendurados nas paredes revelam a ocupação predileta de Seu Castro. Dona Emma justifica o fato: "agora só temos os trabalhos de Castro como enfeite. Os bibelôs e minha louçaria foi toda roubada".

A trajetória geográfica, e a opção por uma morada funcional e protegida, é situada no presente pelo casal de idosos a partir da vulnerabilidade em face de matizes de uma cidade violenta. Para controlar a imprevisibilidade de um cotidiano descontinuo, interpretam os deslocamentos a partir de uma posição volátil na cidade. Outras imagens são relatadas para falar de deslocamentos e de suas trajetórias biográficas como citadinos. 
$\mathrm{Na}$ narrativa do casal, o tempo presente contempla o desafio de atribuírem uma ordenação para os tempos passados diante dessas transformações urbanas. Aos poucos o casal remonta suas trajetórias familiares a partir do seu deslocamento por diferentes bairros quando solteiros, até o momento solene do investimento de compra de uma casa, como parte integrante de um projeto de vida familiar, a partir do casamento e do nascimento dos filhos. Nesse processo, experiências de vida diversas na cidade são restauradas: trajetórias familiares, trajetórias educacionais, percursos na vida profissional, escolhas de formas de lazer, engajamentos em ações comunitárias, sempre acomodados nos deslocamentos e as lembranças das paisagens urbanas da cidade de Porto Alegre da infância à vida adulta, passando pela época de juventude quando se conheceram e começaram a namorar. Operando no plano dos jogos da memória de suas experiências de viver em Porto Alegre, somos levadas, assim, a compartilhar com Seu Castro e com Dona Emma, por meio das figurações que povoam suas narrativas biográficas, as suas experiências vividas nos bairros dessa cidade: as sociabilidades das ruas, das escolas, dos trajetos de bonde e de ônibus, dos footings na Rua da Praia até a preferência pelos deslocamentos que conduzia nosso casal até a confeitaria Rocco ou a livraria do Globo, na área central, para um consumo da elite portoalegrense.

Em especial, as lembranças do Seu Castro sobre o trabalho o animam a recuperar mapas da época de sua atividade como funcionário público na secretaria de obras da Prefeitura. Quando o mapa não é suficiente para traçar sua trajetória de atividades de trabalho, nosso narrador desenha espaços e ruas para narrar suas atividades profissionais, descrevendo as modificações no desempenho de sua profissão como parte da transformação urbana de Porto Alegre. Por seu turno, Dona Emma prefere a oralidade, nos fala dos bairros em que morou, do nome das ruas, das diferentes casas e da paixão pela Escola Medianeira, "queria ser freira". A mudança de vocação provém de outra paixão: a do namoro precoce, mas definitivo. Eles se conheceram por freqüentarem a mesma linha de ônibus: "Ele embarcava no ônibus aqui na Santa Cecília, e eu vinha com esse ônibus da escola. Esse mesmo da Teixeira de Freitas. O fim da linha, era aqui na Santana. Aí ele olhava pra mim, eu olhava pra ele... foi de olho". Ela tinha 14 anos, ele 16 . O casamento não tardou a acontecer. 
O tema predominante para falar da condição atual é a saúde e os filhos. O projeto familiar quanto aos filhos lhes parece bem-sucedido, seja na carreira militar de um filho, seja na de pequeno comerciante de outro filho. Transitando, no espaço fantástico da memória, do tempo passado ao tempo presente, e vice-versa, ambos comentam que os ganhos da aposentadoria tem lhes permitido, hoje, uma dinâmica sazonal de moradia, dividindo-os entre residir no apartamento situado na capital, em Porto Alegre, e, em períodos de clima ameno e calor, a estadia na casa de veraneio em Cassino, já cercada para maior segurança, após uma tentativa de assalto. A preferência por longas temporadas na praia se deve à oficina de marcenaria montada na garagem e onde Seu Castro pode criar sua arte. Em Porto Alegre, passam todo o período de frio ou sempre que precisam recorrer a exames médicos, seja para controlar os problemas cardíacos do Seu Castro, seja para controlar as dores de coluna e de varizes de Dona Emma. Falam das peripécias para os tratamentos médicos. Uma série de nomes de médicos e suas especialidades são citadas, sempre mapeadas por falas do envelhecimento e que trazem a dramática de dores, de doenças, de curas, de autodiagnósticos entrelaçados à fé católica. O simples, mas sempre acessível, Hospital Ernesto Dornelles, próximo ao seu local de moradia, é elogiado a cada cirurgia relatada. Às dificuldades de hoje, às dores do dia de ontem, às pernas inchadas para a consulta prevista para amanhã, misturam as lembranças de sortes e dificuldades da vida que transcorre com a "benção de Deus". Os encontros continuam, com a tônica no cotidiano.

Pouco a pouco, damo-nos conta de que aquilo que é ordenado nas narrativas de ambos, Seu Castro e Dona Emma, conjuga as experiências pessoais que configuram microcosmos de experiências singulares de moradores de uma grande cidade às situações macrocósmicas vividas por outros moradores do mesmo bairro, pertencentes ao mesmo estilo de vida e visão de mundo. Fenômeno este que os situa no interior dos paradoxos de toda ordem da modernidade, nos termos simmelianos, da tragédia da cultura (1934). Nesse conjunto de ações ordinárias relatadas para nossos ouvidos e diante de nossos olhos, os narradores conhecem e reconhecem progressivamente a superposição de tempos e espaços que transcendem a toda uma comunidade de sentido e de pertença, mas que suas próprias biografias veiculam. A cada experiência singular nos bairros e territórios de Porto Alegre, em seus itinerários e trajetórias, relacionam-se dinâmicas institucionais, experiências 
geracionais, histórias de poder e políticas disjuntivas que desvendam as descontinuidades do viver cotidiano por situações de nossa cultura em suas vulnerabilidades, medos, frustrações, desigualdades e conflitos. Essas polifonias e polimorfias que desvendam as descontinuidades da lógica citadina são determinadas por ideologias que tendem a universalizar os problemas e as tensões que dão forma ao estilo de vida na cidade moderna.

Vemos, assim, se entrecruzar as narrativas de uma empregada doméstica com as de um feirante, e estas com as de um torcedor de futebol de várzea, de uma habitué da feira do livro, de um pai de santo e, talvez, por que não, dum catador de lixo, dos moradores do Asilo Padre Cacique etc. Os personagens são diversos, agentes da ação cotidiana. Interpretando suas narrativas, o antropólogo pode então configurar o cenário de suas vidas em uma multiplicidade de intrigas que ritmam a cidade. Falas e gestos que desenham os sistemas de representações simbólicas associados à cidade na contemporaneidade.

Nesse ponto, os jogos da memória nos conduzem aos estudos de narrativa no contexto metropolitano, e nos convidam, por sua vez, a reconhecer a relevância de se explicitar toda uma adesão intelectual singular no campo dos estudos da memória para a pesquisa na área da Antropologia das sociedades complexas. Uma adesão a um campo epistemológico da Antropologia do imaginário na tentativa de percorrer a polêmica que reúne numa harmonia conflitual, o registro individual, o social e o coletivo na consolidação temporal de uma duração. Um desafio que só pode ser dimensionado desde a tripla atribuição do espaço fantástico da memória como a força interpretativa das pluralidades temporais numa grande metrópole contemporânea. Seguindo a obra de Paul Ricoeur (1997) e de Gilbert Durand (1984) podemos, portanto, argumentar que, em cada narrativa contada para nossos ouvidos e restauradas para os nossos olhos, a força da linguagem com que tudo nos é relatado, neste eterno desvendamento do "eu", sendo já a ação sobre o mundo, no plano do transcurso de uma vida vivida, estrutura todo o pensamento dos nossos narradores, ligando-os a uma gramática simbólica, a do vir-a-ser. Antes de ser tempo passado que está em jogo, o que se coloca é a projeção do devir, no presente da narração, que nos faz perscrutar o tempo passado.

Quanto ao tratamento interpretativo que damos ao trabalho da memória, por meio da qual podemos dimensionar numa totalidade de sentido a pluralidade de situações 
biográficas, com as quais estamos habituadas a operar no momento de uma etnografia da duração, importa ressaltar que é o ato de narrar aquele que organiza ritmicamente as lembranças dos "instantes vividos num tempo feliz", e onde a matéria de toda uma vida pode, finalmente, "vibrar" e perdurar (BACHELARD, 1989). Na rítmica da arte de narrar, o interlocutor arranja, em formas significantes, as representações que integram o semantismo que orienta suas evocações às experiências dos tempos vividos, agora narrados, e onde "o símbolo" ao qual aderem "não é do domínio da semiologia, mas do de uma semântica especial, o que quer dizer que ele possui algo mais que um sentido artificialmente dado e detém um essencial e espontâneo poder de repercussão" (DURAND, 1989: 23). Logo, numa etnografia da duração, cada vida narrada ao antropólogo é tomada em sua singularidade. Toda narrativa é apreendida como tendo força interpretativa. O trabalho de pensamento inerente ao ato de configuração narrativa se encerra numa refiguração da experiência temporal (RICOEUR, 1991: 7).

Para essa condição ser aceita, o contexto singular da pesquisa com a etnografia da duração precisa ser evidenciado. Neste caso, é somente por meio da dialética temporal contida no evento etnográfico, reinterpretado pelo contexto pela referência do saber antropológico, que se pode restaurar, por sua vez, o evento da memória narrada em sua significação. Colocar as experiências vividas em narrativa dá um movimento no tempo, da história vivida pelo habitante como anterioridade, tornada presente, agora pública pela narrativa a escuta do pesquisador.

Logo, as experiências temporais narradas ao etnógrafo circulam entre as interpretações etnográficas como construções, no presente, dos tempos vividos e pensados por eles, dando reciprocidade ao deslocamento objetivo e subjetivo de ser-no-mundo, do antropólogo tanto quanto dos seus sujeitos da pesquisa; pois, como postula Paul Ricoeur (1997: 85): “o tempo torna-se tempo humano na medida em que está articulado de modo narrativo; em compensação, a narrativa é significativa na medida em que esboça os traços da experiência temporal" (ibid.: 15).

Essa dialética da vida narrada é situada em Paul Ricoeur a partir do agenciamento dos fatos, sendo então narrativa, "exatamente o que Aristóteles chama de muthos" (ibid.: 63). Esse deslocamento do si-mesmo, configurando o ato de narrar, é a representação do tempo distendido que as aporias de Santo Agostinho (STO. AGOSTINHO apud RICOEUR, 1997: 
23), recolocadas pelo autor, tão bem expressam: "o que é afinal o tempo? Se ninguém me pergunta, sei; se alguém pergunta e quero explicar, não sei mais". Tais aporias tratam, assim, do reconhecimento dramático da ruptura entre o tempo físico e o tempo psíquico, e onde "a questão é pois circunscrita: como o tempo pode ser, se o passado não é mais, se o futuro não é ainda e se o presente nem sempre é" (ibid.:.23).

Para a etnografia da duração junto a diferentes situações de interação e sociabilidade no cotidiano dos habitantes da cidade de Porto Alegre, o procedimento analítico das imagens captadas, das entrevistas e sons gravados, dos vídeos editados, nos motiva a experimentar o exercício interpretativo dessa dialética da memória, entre tempo pensado e tempo vivido, na tessitura da intriga acionada pelo narrador em três níveis de operação, e que estabelece o estatuto da mimética da ação.

Estamos nos apropriando explicitamente dos três níveis da operação mimética (mimeses I, II e III) da ação, propostos por Paul Ricoeur (1997), e que encadeiam os tempos em suas singularidades, da prefiguração, da configuração e da refiguração, respectivamente. Esses tempos de acontecimentos do mundo que nos são narrados durante o trabalho de campo (muitas vezes acompanhados de álbuns de famílias, de recortes de jornais, de objetos de herdados etc.) constituem, para nós, etnógrafos da duração, as mediações simbólicas que tornam presentes os fatos vividos, para os nossos narradores, em sua inteligibilidade narrativa.

Dessa forma, em nossos termos, o ato narrativo passa de um tempo prefigurado da ação, no nível da experiência cotidiana, na ação do mundo como mimese I, e que se transforma em um tempo configurado simbolicamente pela composição narrativa em mimese II (da qual participa o etnógrafo), tendo em vista comunicar uma experiência a alguém (no caso da experiência do trabalho de campo visa a comunidade lingüística do próprio antropólogo). Este terceiro tempo pontua o tempo da alteridade, onde se comunica o narrado para outro alguém, sem que tenha participação da evocação daquilo que foi narrado.

No caso da etnografia da duração, a cidade de Porto Alegre aparece como cenário da cultura urbana local, consolidado em suas feições históricas e sociológicas, graças às sobreposições espaço-temporais a que somente a ordem do espaço fantástico da memória 
de seus habitantes permite aceder. As estruturas que tornam inteligíveis o campo semântico das ações desses habitantes no tempo, e que são constantemente evocadas, por exemplo, no espaço das narrativas aqui apresentadas, dão conta, por sua vez, do processo de transfiguração incessante das formas de vida social dos grupos urbanos. Por outro lado, as memórias dispõem sobre as trajetórias de vida ritmadas nas constantes transformações e mudanças destrutivas e/ou criativas. A confeitaria do Rocco que "eu adorava" (Dona Emma) já não existe mais, é apenas ruínas. E mesmo que ainda existisse, o centro é hoje evitado pelo casal, a não ser que a consulta do médico obrigue a ir ao centro: "nesse caso vamos e voltamos de táxi”.

Eis, assim, o nosso desafio: como apreender essa cultura do tempo? Teremos que enfrentar a compreensão da dimensão de intriga decorrente da ação aos personagens que dimensionam a vida de Porto Alegre. Intrigas que, operadas pelas narrativas na forma de uma tríplice mimese (prefiguração, configuração e refiguração), reúnem, num tempo compartilhado controverso, vidas pessoais, histórias coletivas, lógicas sociais, relações estruturais e organizacionais etc., e cuja tessitura tem por meta fazer concordar tudo aquilo que é, em si mesmo, discordante.

Trata-se de agenciar, na formação da intriga, o reconhecimento do narrador da fragilidade da continuidade de sua recordação, pela vulnerabilidade do ser no tempo que se esvai, onde a narrativa não fecha uma vida vivida na Porto Alegre de ontem, mas a situa na descontinuidade do tempo que é ritmo. O jogo "lembrar e esquecer" é sim um projeto restaurativo, mas ingênuo, diz Benjamin, pois só retoma do passado uma não-identidade de si, pois essa está aberta sobre o futuro, sobre o inacabado, porque, afinal de contas, o drama continua (citamos GAGNEBIN, 1999: 13-6).

Sob este ângulo, nada do mundo objetivado ou subjetivado é aqui materializado como uma realidade de vida do passado, de ontem, em contraste com uma condição presente, de hoje. A interpretação de si-mesmos dos nossos narradores tanto quanto as do etnógrafo, compartilhando experiências do viver urbano, são agenciadas por sua pertença ao mundo dos simbólicos; uma cultura urbana que se transforma a partir dos jogos da memória de seus habitantes, e pela forma como elas potencializem uma dramática do viver cotidiano na cidade. 
Trata-se de um convite, ou antes, se contemplar o acontecimento urbano seja a partir da imagem mnésica que os habitantes enquanto atores sociais sugerem, seja do fundo comum de sentido ao qual pertencem. Tendo por objeto de reflexão as cidades modernas, a ênfase interpretativa dá-se sobre as formas de organização e interação entre indivíduos e suas redes de relações como campos de negociação da realidade em múltiplos planos. Trata-se de reconhecer o tempo urbano vivido através das narrativas de trajetórias e de itinerários de indivíduos/grupos neste jogo de eterna reinvenção de "práticas de interação" de seus habitantes (GOFFMAN, 1974: 42). Assim, pode-se redimensionar a cidade "etnografada" como objeto que realiza uma obra temporal, uma vez que seus territórios e lugares se prestam ao enraizamento de uma experiência de sentidos reinterpretada, sistematicamente, por uma comunidade de comunicação, emitindo múltiplas figurações de uma constante reordenação do viver coletivo.

Podemos concluir que, para nós antropólogos que trabalhamos nas cidades, "narrar a cidade" é a obra da tessitura dos relatos que ordenam memórias, testemunhos, percepções e sentimentos. A memória narrada é a forma da vida citadina ser tomada na inteligibilidade das experiências geracionais, e que situam cada sujeito da pesquisa como um narrador. Tais narrativas são geradas e geram sistemas simbólicos que configuram a rede de significados e o conjunto de valores em torno do qual os habitantes na cidade agenciam suas interações sociais.

Numa etnografia da duração, as narrativas recolhidas pelo antropólogo, em seu ofício, estão ali precisamente para circularem e, assim, provocar novas narrativas, e com elas novas formas de se viver a cidade.

A cidade interpretada se revela, então, como exercício reflexivo de ver-se a si mesma nas transformações profundas tanto quanto nas regularidades e rotinas de uma vida cotidiana. Nesse processo a consciência de si (do antropólogo) também é apreendida na sua gênese. A memória coletiva dos indivíduos ocidentais é também a sua. ${ }^{2}$

\footnotetext{
${ }^{2}$ Citamos aqui o artigo de BOURDARIAS, F., "Norbert Elias: les techniques du regard". In. Sociétés. Revue des Sciences Humaines et Sociales. Paris : Dunod, n. 33, 1991. p. 259.
} 


\section{REFERÊNCIAS BIBLIOGRÁFICAS}

BACHELARD, G. A dialética da duração. São Paulo: Editora Ática, 1988.135 p. . La dialectique de la durée. Paris: Quadrige/PUF (1 ed. 1950), 1989. 130 p.

BOSI, Ecléa. 1987. Memória e sociedade. Lembranças de velhos. São Paulo: Queiroz ED. Ltda. e EDUSP. 400 p.

DE CERTEAU, Michel. 1992. A invenção do Cotidiano. Petrópolis: Vozes. 351 p.

DURAND, Gilbert. 1984. Les structures anthropologiques de l'imaginaire. Paris : Dunod. $350 \mathrm{p}$.

. A imaginação simbólica. São Paulo: Cultrix, 1988,114 p.

1989, $326 \mathrm{p}$.

As estruturas antropológicas do imaginário. Lisboa: Editorial Presença,

ECKERT, C.; ROCHA, A. L. C. da. "A interioridade da experiência temporal do antropólogo como condição da produção etnográfica". In: Revista de Antropologia. Departamento de Antropologia. Faculdade de Filosofia, Letras e Ciências Humanas. Universidade de São Paulo/USP. São Paulo-SP. 1998a. Vol.41 n. 2. p. 107-135.

- Premissas Para O Estudo da Memória Coletiva No Mundo Urbano Contemporâneo Sob A Ótica dos Itinerários de Grupos Urbanos e Suas Formas de Sociabilidade. Margem (PUC/SP), São Paulo, 1998b, n. 8, p. 243-260.

. "O antropólogo na figura do narrador". In: Habitus, Revista do Instituto de Pré-História e Antropologia. Universidade Católica de Goiânia. Goiânia, GO, Ed. da UCG. 2003.Vol. 1, n. 2, jul./dez. p. 395-420.

2005. $198 \mathrm{p}$.

O tempo e a cidade. Coleção Academia II. Porto Alegre: Ed. da UFRGS,

GABNEBIN, J. M. História e narração em Walter Benjamin. São Paulo: Editora Perspectiva, 1999, $114 \mathrm{p}$.

GRAEF, L. O mundo da velhice e a cultura asilar. Estudo antropológico sobre memória social e cotidiano de velhos no Asilo Padre Cacique, em Porto Alegre. Porto Alegre, Dissertação de mestrado PPGAS, UFRGS. 2005. 300 p.

GOFFMAN, E. Les rites d'interaction. Paris: De Minuit, 1974, 274 p. 
HALWBACHS, M. La mémoire collective. Paris: PUF, 1950, 250 p.

RICOEUR, P. 1991. O si-mesmo como um outro. Campinas-SP: Papirus. 1998. 432 p. . Tempo e Narrativa. Vol. I. Campinas-SP: Papirus, 1997, 327 p. Tempo e Narrativa. Vol. III. Campinas-SP: Papirus, 1998,. 432 p. . La mémoire, l'histoire, l'oubli. Paris: Seuil, 2000, 670 p.

SAHLINS, M. Ilhas de História. Rio de Janeiro: Zahar, 1985, 220 p.

SANSOT, P. Les formes sensibles de la vie sociale, Paris: PUF, 1997, 213 p.

SIMMEL, J. Cultura femenina y otros ensayos. Madrid, Revista de Occidente, 1934, 300 p.

SIMMEL, G. "A metrópole e a vida mental" In: VELHO, ${ }^{\circ}$ G. (org). O fenômeno urbano. Rio de Janeiro: Zahar, 1979, pp. 11-25. . Sociologie et Epistémologie. Paris: PUF, 1981, 240 p. . Questões fundamentais da sociologia. Rio de Janeiro: Jorge Zahar, 2006, 120 p.

VELHO, G. A Utopia Urbana: um estudo de antropologia social. 6. ed. Rio de Janeiro: Zahar Editores, 1973, v. 1. 115 p.

Individualismo e Cultura: notas para uma antropologia da sociedade contemporânea. 1. ed. Rio de Janeiro: Zahar Editores, 1981, v. 1. 149 p. 


\section{Para citar essa obra:}

ROCHA, Ana Luiza Carvalho da; ECKERT, Cornelia. Cidade narrada, tempo vivido: estudos de etnografias da duração. RUA [online]. 2010, no. 16. Volume 1 - ISSN 14132109

Consultada no Portal Labeurb - Revista do Laboratório de Estudos Urbanos do Núcleo de Desenvolvimento da Criatividade http://www.labeurb.unicamp.br/rua/

Laboratório de Estudos Urbanos - LABEURB

Núcleo de Desenvolvimento da Criatividade - NUDECRI

Universidade Estadual de Campinas - UNICAMP

http://www.labeurb.unicamp.br/

Endereço:

Rua Caio Graco Prado, 70

Cidade Universitária “Zeferino Vaz" - Barão Geraldo

13083-892 - Campinas-SP - Brasil

Telefone/Fax: (+55 19) 3521-7900

Contato: http://www.labeurb.unicamp.br/contato 